\title{
A Study on CLL Method in Reading Course
}

\author{
Yan Zhang \\ Zhengzhou Institute of Aeronautical Industry Management, Henan, China \\ Email: yanzh617@sina.com
}

\begin{abstract}
This paper, by comparing the effects of cooperative language learning (CLL) with that of individual-oriented traditional teaching method, seeks to explore the effective use and possible problems of cooperative language learning in college foreign language teaching. The academic achievement, retention of academic content and attitudes towards the teaching methods are used as criteria to determine the effectiveness of the two methods in classroom.
\end{abstract}

Index Terms - cooperative language learning, foreign language teaching, college stage

\section{INTRODUCTION}

Cooperative learning is an old idea in our country. There was a record of "if one learns alone and without friends' help, he will be ill-informed" in the classical educational book XueJi 2000 years ago, which emphasizes cooperation in the learning process. According to Slavin (1995), such educational theorists as Comenius in the seventeenth century, Rousseau in the eighteenth century and Pestalozzi in the nineteenth century held some forms of cooperation among students as essential to learning. Although the term "cooperating learning" is formally put forward in 1970s, there is no consensus on which theory is the recognized basis of cooperative learning. Slavin (1995) found the theories fall into two major categories: motivational and cognitive. According to Johnson, Johnson \& Holubec (1998, cited in Johnson \& Johnson, 2000), cooperative learning has its roots in social interdependence, cognitive-developmental, and behavioral learning theories. While there are different views on the attributes of cooperative learning, five essential elements--positive interdependence, individual accountability, face-to-face promotive interaction, interpersonal and small group skills, and group processing -- are embedded in many models of cooperative learning (Johnson \& Johnson, 1989, 1991, 2000). These elements are considered central to cooperative learning. Only under the full use of basic factors can efforts be created among members. Practitioners have developed many cooperative learning methods, which are based on the integration of the essential elements into each cooperative activity or assignment.

Deutsh (1949, cited in Johnson \& Johnson, 1991) conceptualized three types of goal structures that organize interpersonal behavior: cooperative, competitive, and individualistic. In the competitive goal structure, students work against each other to achieve a goal that only one or a few can attain. Students would be given the task with competing to see who completes it faster and more accurately than others in the class. They are wanted to work independently without discussing with other students and to seek only assistance from the teacher. In an individualistic situation, there is no correlation among the goal attainments of the participants. Students would be given the task completing to reach a present criterion of excellence. Education, especially foreign language education in most countries, had been on a competitive and individualistic basis.

In the cooperative learning classroom, students are assigned to small groups and instructed to learn assigned material and to make sure that the other members of the group also master the assignment. An individual can reach his learning goal if and only if the other participants in the learning group also attain their goals. Students help each other and benefit both of them in the cooperating student-student and teacher-student relationship. Even though these three goal structures are effective in helping students learn concepts and skills in some conditions, students can learn to interact more effectively and positively in cooperative learning process. Compared with competitive and individualistic goal structure, therefore, cooperative goal structure should be the best choice in our life, schooling, family, career, etc. Hundreds of studies on the efficiency of cooperative learning associated with competitive or individual performance during the past century have been conducted by researchers with different age subjects, in different subject areas, and in different environments.

Cooperative learning has been found to be effective for promoting learners' the academic achievement, language acquisition, and communicative skills. Theory and research in the area of second language acquisition suggested that cooperative learning should also help second language learners acquire English. Sharan et al. (1984) has shown positive effects of cooperative learning on learning English as a foreign language. Freed (1994) investigated the effect of cooperative learning on EFL reading and found the experimental groups showed positive attitudes and more enhanced enjoyment and motivation. Szostek (1994, cited in Chafe, 1998) conducted an informal study of cooperative learning in a Spanish honors foreign language classroom and found students and observers were very positive about the cooperative learning experience in this study. Careen (1997, cited in Chafe, 1998) in a study of cooperative learning in French foreign language class found students of all levels in the cooperative learning groups acquired significantly more vocabulary than that of the traditional methods. 
In sharp contrast to traditional language learning, cooperative language learning (CLL) reflects the integrative and communicative aspects of language learning, and is in accordance with the advocating of communicative language teaching and student-entered instruction in teaching foreign language (Johnson \& Johnson, 1991; Nunan, 1989; Zhang, 2010). CLL takes activities to train learner's language and social skills through discussion and communication in the form of small group. It provides much more opportunities for learners to comprehensible input and output and the processes of negotiation. Students are motivated to be engaged in language learning classroom, which leads to greater language proficiency. It provides learners more chances to produce language in a functional manner (Crandall, 1999). More importantly, it greatly fosters learners' responsibility and independence in language learning so that they could improve their cooperative and interactive skills which are indispensable in modern society.

In 1990s, educators in China began to apply group work in classroom, which initiated the exploring research on cooperative learning. In recent years, cooperative learning has received much attention as an alternative to the lecture format by the foreign language educators at college level. The review of a few of relevant studies on cooperative learning suggests that cooperative learning should be beneficial for EFL classrooms at college level in China. For example, Su and Zhang et al. (2000) showed cooperative learning could successfully improve listening comprehension, and enhance the teacher-centered listening classroom. Zhang and Zhao (2004) explored how to put cooperative learning into the practice of promoting the teaching quality of college English reading class and established a new type of fast and effective student-centered teaching model for reading course. Li (2007) acknowledged the advantages of cooperative learning such as increasing students' opportunities to practice the language, enhancing their confidence in English language learning, establishing good relationship and promoting students' active learning and so on and proved that students in the large-class English teaching had a positive attitude towards cooperative learning. Deng and Chen (2010) in a study of cooperative learning in reading class found the impact of the cooperative language learning environment on students' metacognition differed from that of the traditional learning environment, yet the promoting impact on the metacognition and reading ability had not manifested itself to the full extent. Shi and Ji (2010) in a training on students of science and engineering verified that cooperative learning is effective in promoting students' learning performance and their use of autonomous learning strategies and ability.

Although a considerable volume of research in our country have demonstrated the effectiveness of cooperative pedagogical strategies, cooperative learning at the college level are limited in number. Most college-level studies in the field of foreign language learning provide the explanations of theory or some specific procedures of carrying out cooperative learning methods and suggestions on how to adopt it in classroom. Little has been done with the experimental inquiry. The actual effect of CLL has not been deeply exploited. In an attempt to move the process along, the author of the paper conducted an experiment with the selected CLL methods in order to explore the effective use and possible problems of CLL in college foreign language teaching and learning.

\section{Methodology}

\section{A. Aims and Questions}

In spite of great changes in the field of language teaching during the past few decades, TEFL in china remains mainly traditional. Traditional methods here refer to the teacher-centered methods which are principally individual-oriented or competitive-oriented. Thus comparing CLL with non-cooperative traditional methods gives us a clear picture of the effectiveness of the CLL method in language learning and teaching. The philosophy and principles that formed the basis of the experimental course design have been articulated by Slavin (1995) and Johnson, Johnson \& Smith (1991). The techniques for organizing group work are suggested by Glosser (2012), Felder \& Brent (1994), and many other books and articles in the recent education literature. The objective of the study is to determine the teaching effects of cooperative language learning approach for EFL learners in Chinese context on the achievement, retention for text content, and attitude toward the instructional methods of selected English majors. These purposes are turned into following questions:

1. Will there be a significant difference in academic achievement between the students taught by using the CLL method and those by using the traditional method?

2. Will there be a significant difference in retention of academic content between the students taught by using the CLL method and those by using traditional method?

3. What are students' attitudes towards CLL in class?

\section{B. Subjects}

A total number of 102 grade-two English majors in Foreign Languages Department of our institute participated in this study. The experimental group $(\mathrm{N}=52)$ randomly selected are two natural classes from four natural classes in this grade.

\section{Procedures}

The study consists of three parts: pretest, lecture, and two posttests. The experimental groups and control groups are four natural classes. It is necessary to give them a proficiency test before the study. Therefore, at first, all the students are given the same English proficiency test. Then the four classes receive the same instructional material. In order to 
control the "teacher quality" variable, the control classes are taught by their former teachers. All groups are taught the same content, but students in experimental classes complete the learning tasks by using cooperative learning methods, while the students in the control classes complete learning tasks in a traditional learning way. The experimental classes $(\mathrm{N}=52)$ and control classes $(\mathrm{N}=50)$ are not differing substantially in composition by gender and age. The lessons are taught to all classes over eight weeks' session; each week includes four periods (a period is defined as fifty minutes). One important point should be mentioned is that all participants do not know they will be tested after a period of learning so as to avoid the interfering of factitious factors.

At last, the same quiz paper is given to participants to measure their achievement. The question items of quiz are related to the content of instruction. Three weeks later, the test is administrated again to the students to determine their retention of academic content. As a part of the posttest in this study, the experimental classes are asked to evaluate their experience by answering question: "which do you prefer, CLL method or traditional method? Why?" while the control classes are not asked to evaluate their experience.

\section{Teaching Design}

At the beginning of the experiment, students work in groups of their own choice. Since CLL involves a great deal more than simply placing students into groups, the teacher sets aside an entire 50-minute period for assigning the groups and talking to the students the requirements and potential outcomes of using CLL. The group members are mainly chosen by their ability and individual difference so each group will have one top-level, two middle-levels and one struggling student. Students assign roles within group, which includes one reader, one speaker, one recorder and doubling as timer, one or two responders (their roles are rotated every other assignment or fixed according to the learning task). They are encouraged to challenge each other and the teacher. They assess the class performance of their members and themselves after a certain time of learning.

The appropriate CLL methods are employed according to the teaching content. The teacher assesses group performance by circulating among the students to monitor their discussions and by listening to their answers. After each cooperative learning activity, the teacher gives credits to those groups if group members make progress, and marks down those groups if group members fall behind. Students win points by demonstrating knowledge of the academic material that has been practiced in team and earn extra points by correctly challenging the answer of other group. The teacher also explains the difficult and important language points if necessary. Meanwhile, they are required to follow a list of cooperative learning activity rules (referenced on Glosser, 2012):

1. Every member of each group is responsible for himself and his group work.

2. Every member should be constructive and honest to contribute to the group.

3. Be open to other members' ideas and encourage everyone's participation.

4. No Chinese is allowed when doing the group work.

Before the formal start of the experiment, the author consciously began to implement in class the more basic cooperative learning activities such as Roundtable, a Rapid Brainstorming, and then relatively highly structured activities such as Solving Problems with Cooperative Learning, Cooperative Integrated Reading and Composition. Several weeks later, positive interdependence was promoted among team members, individual accountability assured for most of group work, and teamwork skills developed. Students had been used to cooperative learning in language learning. In such condition, the author formally carries out the experiment.

The control classes are taught by using the traditional non-cooperative approaches. This approach has been used for a long time in teaching either intensive reading course or other courses. The main pattern is "teacher talks, students listen". The teacher may occasionally uses team work or other activities to develop the teaching, which depends on the teacher's own teaching style.

\section{E. Measures}

The dependent variables in this study are two posttests scores for academic achievement and retention of academic content. Achievement is measured by test score. The independent variable is method of instruction: cooperative language learning and non-cooperative learning.

\section{RESUltS AND DiSCUSSION}

At first, an independent-samples t-test is conducted on two treatment groups' proficiency tests. The mean of the pretest scores of the participants in the group that learn cooperatively $(M=91.86)$ is not significantly different from that of the group who learn traditionally $(\mathrm{M}=90.10)$. The $\mathrm{t}$-test yields a value $(\mathrm{t}=0.708, \mathrm{p}=0.481)$, which is not statistically significant. Hence, it is concluded that the two groups are not significantly different (see table 1).

TABLE 1

COMPARISON OF TWO GROUPS' ENGLISH PROFICIENCY LEVEL

\begin{tabular}{|l|l|l|l|l|l|}
\hline Group & $\mathrm{n}$ & Mean & SD & $\mathrm{t}$ & $\mathrm{p}$ \\
\hline Experimental group & 52 & 91.86 & 12.00 & 0.708 & 0.481 \\
\hline Control group & 50 & 90.10 & 13.16 & & \\
\hline
\end{tabular}


The dependent variables of student academic achievement and retention of academic content are analyzed with a simple test of differences in the mean scores of the two groups, using a t-test for independent samples. In achievement, as measured by total test scores, the cooperative group outperformed the non-cooperative group $(\mathrm{t}=2.60, \mathrm{p}=0.011)$. There is a significant difference in student achievement between the students taught by using CLL method and those by using non-cooperative traditional method. In the retention of learned knowledge, the two groups also show significant difference $(\mathrm{t}=2.45, \mathrm{p}=0.016)$ (see table 2$)$.

TABLE 2

ACHIEVEMENT OUTCOMES, RETENTION FROM USING COOPERATIVE AND INDIVIDUAL-ORIENTED LEARNING METHOD
\begin{tabular}{|l|l|l|l|l|l|l|l|l|l|}
\hline & Achievement test & Retention test \\
\hline Group & N & Mean & SD & t & p & Mean & SD & t & p \\
\hline Experimental group & 52 & 79.23 & 9.09 & 2.60 & 0.011 & 68.85 & 16.87 & 2.45 & 0.016 \\
\hline Control group & 50 & 74.48 & 9.34 & & & 60.38 & 18.04 & \\
\hline
\end{tabular}

According to the statistical analysis on the test scores, the hypothesis that employing CLL strategies in college classrooms for EFL learners can improve students' achievement and retention is supported. The results match the learning theories proposed by proponents of cooperative learning. Slavin (1990) proved that interaction among students around appropriate tasks increases their mastery of academic contents. When students interact with other students, they need to explain and discuss each other's opinions, which will facilitate further understanding and memory of the material to be learned. The debate to resolve potential conflicts during cooperative activities results in the development of higher levels of understanding and long-term memory, so the students who employ CLL methods in experimental group have the higher achievement than those who are in the control group. Likewise, the result shows the different retention level in the second posttest, which corresponds with the findings of many researchers. According to Johnson et al. (1986), cooperative learning activities enhance more frequent giving and receiving of explanations, which has the potential to increase the accuracy of long-term retention. However, it is noted that the mean of the participants in the group that learn cooperatively $(M=79.23)$ shows but a little higher than that of the group who learn traditionally $(\mathrm{M}=74.48)$. Possible reason for this may have been the high learner motivation. The experiment period is coincidentally near to the date when sophomores have their National English-majors Band 4. The high extrinsic motivation has prompted them to duly review what they have learned in class and especially to memorize a large mount of new words and expressions.

At the end of the experiment, the participants in the experimental group are given an open-ended question in which they tell whether the new method is helpful. Among 52 effective questionnaire papers, 40 papers answer positively. Generally speaking, we can probably believe that CLL has produced positive feelings in the students. When asked why, most participants provide two to three reasons. Table 3 and 4 list their most common responses in rank order (concluded by general ideas).

TABLE 3

MAJOR REASONS FOR COOPERATIVE LEARNING ACTIVITIES

It provides me more chances to practice oral English.

I make deeper understanding on the learning materials and remembered the new words more quickly.

I am concentrated more.

I feet relaxed in group work.

I must be self-disciplined to preview and review my learning task for the benefit of my group.

I get to know more about my classmates.

I learn to be responsible for my words and actions.

TABLE 4

MAJOR REASONS AGAINST COOPERATIVE LEARNING ACTIVITIES

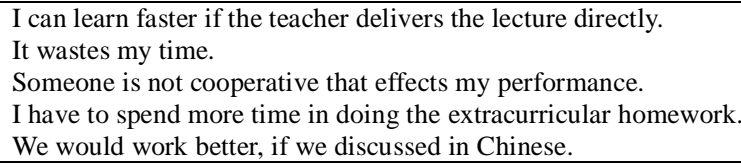

When the students are asked to list their reasons for supporting CLL method, they display their communicative need. With the expanding communication with western countries and the great emphasis on spoken English in china's educational reform, students as individuals have realized the importance of communicative function of language, and they urge to get more chances to practice their oral English. CLL activities just meet their needs. During the CCL work, students themselves could be the teachers when explaining and arguing with their peer, thereby the process reinforces their memory of newly learned language. Students put top priority on the mastery of knowledge of English as well as the acquiring of social skills such as responsibility and cooperation. Due to cooperative "we-win, I-win" rather than traditional "I-win, you-lose" structure, many students have to commit a large amount of time and effort to the course materials for the benefit of group and themselves than they would have done in a passive, note-taking lecture environment. Students also regard this method as a facilitator to concentrate themselves on learning in class in order to perform well. Inevitably they would improve their performance at school. Students consider CLL can create a positive 
and embracing climate in which they can learn more.

In the responses against CLL, some students cannot accustom themselves to learning with others. They are more likely to accept what the teacher arranged for them. Some students mention that they have wasted a lot of time on explaining the materials to other group members. Those students are investigated to be the able ones, partly because they as independent adult with strong thinking ability and self-consciousness are not liable to cooperate with each other to accomplish tasks, partly because some insecure students may choose to be uncooperative or silent. Some students pay excessive attention to memorizing the vocabulary and doing the simulated tests for the preparation of upcoming exam. Some top students who are eager to review for testing even regarded the activities time-wasting. This may influence their attitudes toward CLL and their motivation to participating in the group work. At last, some may overuse their mother tongue in order to communicate easily with group members. They think they would communicate better in group work if they were allowed to speak Chinese instead of English. Low proficiency in English hinders some students from rapid completing of the group work. Actually the activity rule intends to help them practice their oral English as often as possible.

\section{CONCLUSION AND IMPLICATIONS}

From the above analysis we can see the result of the experimental study is rather satisfying despite the fact that this experiment is small-scaled one. It suggests the application of CLL in colleges can be beneficial for foreign language learning in academic performance. However the practical application of this method may raise some issues. On the part of teachers, they may feel it hard to control the teaching process due to the influence of the whole teaching program; they may not balance well time distribution of plain instruction and CLL activities. Students are social individuals each with vastly different needs, learning styles, goals and abilities. The teachers must focus attention on the individual needs of the students. Therefore how to integrate skillfully CLL with class presentation and individual learning and how to take full advantage of CLL need to be further investigated and validated. In addition, teachers are required to possess higher organization ability in class activates. They need to find an appropriate way to use cooperative learning that is congruent with their philosophies and practice. They should carefully prepare tasks or questions for students to accomplish together and arranges well for them to do their work together. They should notice that their role changes from being in front of the learners doing most of the talking to being facilitator, negotiator, and monitor to assure the elements of CCL are successfully implemented. Anyway, from simply providing course content in class to meeting psychosocial needs of the individual student while teaching is just what the teaching paradigm shift about.

\section{ACKNOWLEDGEMENT}

This paper is the product of the Soft Science Project of Henan province (No. 112400450326).

\section{REFERENCES}

[1] Chafe, A. (1998). Cooperative Learning and the Second Language Classroom. http://www. Stemnet.nf.ca/achafe/home-index.html (accessed 1/5/2003).

[2] Crandall, J. (1999). Cooperative language learning and affective factors. In Arnold, J (Eds.) Affect in Language Learning. Cambridge University Press. Beijing: Foreign language Teaching and Research Press, 2001, 226-245.

[3] Deng, Hai \& Che, Yu. (2010). An Empirical Study of the Impact of Cooperative Language Learning on Students' Metacognition. Foreign Language World. 6, 57-63

[4] Felder, R.M., \& Brent, R. (1994). Cooperative learning in technical courses: Procedures, pitfalls, and payoffs. ERIC Document Reproduction Service. http://www2.ncsu.edu/effective_teaching/ (accessed 1/11/2007).

[5] Freed, S. (1994). Cooperative Learning and EFL Reading Comprehension. http://www.surrey.ac.uk/ELI/freeds.html (accessed 21/3/2003).

[6] Glosser, G. (2012). Cooperative learning Technique. http://www.mathgoodies.com/articles/coop_learning.html (accessed $1 / 6 / 2012)$.

[7] Li, Jieli. (2007). Study on the Feasibility of Cooperative Learning in Large College English Class. Journal of Xi' an Foreign Languages University. 15(3), 97-100

[8] Johnson, D.W., \& Johnson, R.T. (1991). Learning Together and Alone: Cooperative, Competitive, and Individualistic (3 ${ }^{\text {rd }}$ Edition). Englewood Cliffs, NJ: Prentice Hall.

[9] Johnson, D.W., \& Johnson, R. T. (2000). Cooperative Learning Center. http://www.co-operation.org/ (accessed 15/4/2003).

[10] Johnson, D. W., \& Johnson, R. (1989). Cooperation and Competition: Theory and Research. Edina, MN: Interaction Book Company.

[11] Johnson, D.W., Johnson, R.T., \& Holubec, E.J. (1986). Circles of learning: Cooperation in the Classroom. Edina, MN: Interaction Book Company.

[12] Johnson, D., Johnson, R., and Smith, K. (1991). Active Learning: Cooperation in the College Classroom. Edina, MN: Interaction Book Company.

[13] Nunan, D. (1989). Designing Tasks for the Communicative Classroom. Cambridge, UK: Cambridge University Press.

[14] Sharan, S. et al. (1984). Cooperative Learning in the Classroom: Research in Desegregated Schools. Hillsdale, N.J.: Erlbaum.

[15] Shi,Jinfang \& Ji, Rongqin. (2010). Fostering Science-and-Technology Students Autonomy in Web-based Learning Environment: An Empirical Study Based on Cooperative Learning. Journal of Xi' an Foreign Languages University . 18(2), 97-100 
[16] Slavin, R.E. (1990). Cooperative Learning: Theory, Research, and Practice. New Jersey: Prentice Hall.

[17] Slavin, R. E. (1995). Cooperative Learning: Theory, Research, and Practice ( $2^{\text {nd }}$ edition). Boston: Allyn and Bacon.

[18] Su, Zhenli, et al. (2000). Application of Controlled learning and Cooperative Learning in Teaching English Listening. Computer-assisted Foreign Language Education. 75(3), 36-40.

[19] Zhang, Fake \& Zhao, Ting. (2004). The Application of Cooperative Learning Theory in College English Reading Class. Computer-assisted Foreign Language Education. 104(6), 46-51.

[20] Zhang, Yan. (2010). Cooperative Language Learning and Foreign Language Learning and Teaching. Journal of Language Teaching and Research.1(1), 81-83

Yan Zhang was born in Henan, China in 1977. She is currently a lecturer in the foreign languages department, Zhengzhou Institute of Aeronautical Industry Management, Henan Province. Her research interests include EFL teaching and learning, language testing and teaching methodology. 